Article

\title{
Can Urban Forest Settings Evoke Positive Emotion? Evidence on Facial Expressions and Detection of Driving Factors
}

\author{
Ping Liu ${ }^{1}$, Mengnan Liu ${ }^{1}$, Tingting Xia ${ }^{1}$, Yutao Wang ${ }^{1, *}$ and Hongxu Wei ${ }^{2,3, *(D)}$ \\ 1 College of Forestry, Shenyang Agricultural University, Shenyang 110866, China; lp_79@syau.edu.cn (P.L.); \\ lmndeyouxiang@163.com (M.L.); xtt3939@163.com (T.X.) \\ 2 Key Laboratory of Wetland Ecology and Environment, Northeast Institute of Geography and Agroecology, \\ Chinese Academy of Sciences, Changchun 130102, China \\ 3 University of Chinese Academy of Sciences, Beijing 100049, China \\ * Correspondence: ytw730@syau.edu.cn (Y.W.); weihongxu@iga.ac.cn (H.W.); Tel.: +86-24-8848-7150 (Y.W.); \\ +86-431-8253-6084 (H.W.)
}

check for

updates

Citation: Liu, P.; Liu, M.; Xia, T.; Wang, Y.; Wei, H. Can Urban Forest Settings Evoke Positive Emotion?

Evidence on Facial Expressions and Detection of Driving Factors. Sustainability 2021, 13, 8687. https:// doi.org/10.3390/su13168687

Academic Editors: Angeliki

Paraskevopoulou and

Chrisovaladis Malesios

Received: 30 June 2021

Accepted: 2 August 2021

Published: 4 August 2021

Publisher's Note: MDPI stays neutral with regard to jurisdictional claims in published maps and institutional affiliations.

Copyright: (C) 2021 by the authors. Licensee MDPI, Basel, Switzerland. This article is an open access article distributed under the terms and conditions of the Creative Commons Attribution (CC BY) license (https:/ / creativecommons.org/licenses/by/ $4.0 /)$.

\begin{abstract}
There is increasing interest in experiences of urban forests because relevant studies have revealed that forest settings can promote mental well-being. The mental response to a forest experience can be evaluated by facial expressions, but relevant knowledge is limited at large geographical scales. In this study, a dataset of 2824 photos, detailing the evaluated age (toddler, youth, middle-age, and senior citizen) and gender of urban forest visitors, was collected from Sina Weibo (a social media application similar to Twitter in China) between 1-7 October 2018, in 12 randomly chosen cities in China. Happy and sad expressions were rated as scores by FireFACE software V1.0, and the positive response index (PRI) was calculated by subtracting sad scores from happy scores. Regional environmental factors were collected to detect driving forces using regression analyses. Happy scores were higher in forests than in urban settings, while sad scores for toddlers were lower in forests than in promenades and squares. Females showed more positive emotional expressions than males. Increases in happy scores were driven by the increase of daily minimum temperature; while PRI declined with increases in latitude. Overall, an urban forest experience can evoke positive emotions, which is likely due to comfortable feelings in warm temperatures.
\end{abstract}

Keywords: green infrastructure; forest bathing; sustainable urban forestry; functional services; sentimental response

\section{Introduction}

Urbanicity is associated with mental stress that increases the risk of poor public health [1]. Urbanization is linked to several stressors, such as traffic, traffic-related air pollution and noise [2], the urban heat effect [3], and social-contact-based anxieties [4,5]. Exposure to urban built settings also hampers recuperation from stressors [6]. Stress is the process by which an individual responds psychologically, physiologically, and often behaviorally, to a situation that challenges or threatens their well-being [7]. Poor mental health plays a central role in stress-caused decline of subjective well-being [8,9]. Improving mental health is a significant goal of urban planners establishing sustainable cities [10].

Urban forests, a type of green infrastructure, address diverse urban challenges and are critical components of urban sustainability [11]. Significant and increasing evidence demonstrates that walking and staying in an urban forest setting can bring mental wellbeing by generating positive emotions or countering negative emotions [12,13]. Relevant studies were usually conducted using a crossover design [14-16]. Therein, subjects in forest settings were taken as respondents while the controlled subjects spent time in urban settings and they would exchange routes the next day [14]. A recent review of recent studies, which were mostly conducted in Asia and Europe, indicated that a forest experience can be effective in reducing short-term mental health symptoms, particularly anxiety [17]. 
Nearly all current research supporting the positive effect of forest experiences on mental and psychological states were obtained from self-reported scores on questionnaires. This methodology has been questioned since 1989 [18]. Fatigue, social habitat, and concerns of group norms may lower the precision of self-reported results. Questionnaires are inefficient and time-consuming [19]. Lack of validation for the accuracy of results may be the most limiting aspect and cause for skepticism [20]. Impacts from subjective perception and subconscious bias are difficult to avoid unless some alternative approach is employed.

Emotions are psychological states associated with all of the nerve systems [21]. Emotions are brought on by neurophysiological changes associated with responses in thoughts, feelings, and behaviors to objective stimuli. Emotions can be aroused by positive and negative thoughts to a degree of pleasure or displeasure, respectively [22]. Perceptive emotions were used as a gauge to evaluate the psychological responses of participants to experiences in forest settings [16,23-25]. Participants reported that they perceived more positive emotions in a forest environment compared to in urban settings [26]. However, higher self-reported scores that indicated better emotions were sometimes also the result of a maintained emotional state in a forest but a sharp decline of positive emotions in an adjacent promenade [23]. Participants also reported the same level of emotional responses with no statistical difference between experiences in a forest vs. urban settings [25]. Selfreported scores on questionnaires highlight the subjective impact on results, suggesting study outcomes might not be repeatable. Varieties in scattered studies across the world further increase the uncertainties of detecting the emotions of people exposed to forests.

Facial expressions are the motions or positions of muscles beneath the skin of the face which convey the emotional state of an individual to observers [27]. Facial expressions are taken as a gauge that reflects immediate emotions with higher accuracy than selfreported scores on questionnaires [28-30]. Recent studies have utilized the the facial expressions of urban forest visitors in different locations [28,31], local environments [30], and demographic variations [29]. Together, these studies have demonstrated the possibility and success of face-reading technology in rating the mental well-being of people in urban forests. The majority of current studies, not only those using face-reading technology but also those using questionnaires $[4,5,12,14]$, were conducted on small scales. Findings likely suffered limits from a larger geographical range. A recent study on the unconscious facial expressions of people indicated that not all urban forest experiences can evoke positive emotions [29]. Based on the current literature, it is necessary to detect the emotional response of urban forest visitors to urban forest experiences using facial expressions at regional or larger geographical scales to test the objectivity of the results.

Lack of large-scale assessment of emotions generates a knowledge gap about the effect of forest experiences on mental health. Using the questionnaire methodology, a total of 14 pairs of forest-vs-urban settings across cities in Japan were included in a study, generating the study with the largest geographical scale on psychological states [32]. This study corroborated findings that an experience in a forest setting can elicit a more positive mental response than that in an urban setting, and found relationships with micro-environmental factors. The total number of participants, however, was 168, which would unlikely account for results at any larger scales. On the other hand, face-reading technique can swiftly evaluate photos and give results about emotional responses at any geographical scale. Using data from social network services, Wei et al. [28] collected a total of 935 selfies and quantified the facial expressions of visitors in nine forest parks from three cities. These studies suggest a potential for success at detecting mental well-being from facial expressions using big data at the national scale. Furthermore, the mechanisms of the driving forces that shape people's emotions can also be detected by monitoring regional environmental records and bridging the relationship with expressional scores.

High temperatures have been considered to be one driver that makes people feel uncomfortable in forest settings [32]. High humidity was found to be the force that made people show more happy faces [30]. In this study, we continue to use the face-reading technique on photos from social network service websites. Demographics and regional 
environments were documented to detect the driving forces. The goal of this study was to test different emotional responses of visitors in city vs forest settings using facial expression scores at the national scale. We also aimed to test the interaction of forest experience with factors of city variation, and evaluated gender and age of the subjects on facial expressional scores. These factors affect psychological and mental states that cannot be avoided when analyzing facial expressions. The novelty of this study comes from the use of face-reading techniques in evaluating the emotional response of people walking and staying in urban forests at a large geographical scale. We hypothesized that: (i) positive expression scores will be higher for people in forests than for those in urban settings. Regarding previous findings [30,32], we also hypothesized that (ii) temperature and humidity differentiates the facial expressions of people in different locations.

\section{Materials and Methods}

\subsection{Study Area and Data Source}

This study focused on 12 cities that are mostly located in central and eastern China (Table 1). The specific geography of studied forest and promenade locations are shown in Figure 1. In accordance with Wei et al. [28], National Day of China in 2018 was chosen as the social hot-spot event, which facilitated the efficient collection of a large dataset from social networking services websites [33]. The National Day also marks the start of a 7-day holiday known as "golden week" [34]. Sina Weibo was used as the source of photo data containing checked-in location information because the information was completely accessible to the public $[28,35]$. Weibo is the biggest social network service (SNS) platform in China, publishing the largest number of microblogs by Chinese users. We focused on cities from the eastern regions of China, where there would be a greater potential for tourists than cities in western regions. We required 20 individual photos to include a city, and many western cites can meet this requirement in China. This generated a pool of cities that met our design requirements. Therefore, we randomly chose 12 cities from this pool of cites instead of that in a larger range across mainland China. An urban forest park and a fully built impervious area (a promenade or a square) were targeted in each city for the locations that were matched by photo records. There were multiple urban forest parks and fully built impervious areas in one city, but the one with the highest number of check-ins during the 7-day National Day holiday was used for the study.

Only people with typical oriental face characteristics were targeted as subjects for the collection of facial photos. We also found some casual faces with obvious facial characteristics from western races, but we chose to focus on oriental faces to detect responses from the most typical group of tourists and eliminate error from casual subjects. Photo collection started at 24:00 on 30 September to 24:00 on 7 October 2018. A total of 1849 photos were collected from people in urban settings, and the number of forest visitors were 975. Most of collected photos were selfies, while others were taken by another person. All photos were taken intentionally because subjects' eyes were visible through the camera lens. The procedures and requirements to collect photos for academic study uses were in full accordance with the ethical standards of The Ethics Committee of the Research Group of Urban Forest and Wetland, Northeast Institute of Geography and Agroecology, Chinese of Academy of Sciences (UFW-EC-2018-001). All authors and mechanicians who had a chance to touch and manage facial expression data were fully required to keep photos classified and use them only for academic study, without disclosing the data to third parties or using them for other business purposes.

Daily temperature and relative humidity records were collected for the analysis of driving forces because they can influence people's psychological perceptions [30,32]. Daily environmental records (mean, maximum, and minimum) were retrieved from the Climatic Data Centre of National Meteorological Information Center of China [36]. Weather records were derived from city-wide stations. Topographic gradients of longitude and latitude information was also recorded as parts of the potential driving forces because their gradients can be related to change in regional climates [37,38]. 
Table 1. Summary of information about city and forest places and numbers of female and male visitors in cities during the National Day of China in 2018.

\begin{tabular}{|c|c|c|c|c|c|c|}
\hline City Name & Place & Name of Place & Coordinate & Female & Male & Total \\
\hline \multirow{2}{*}{ Harbin } & City & Zhongyang Street & $45^{\circ} 46^{\prime} \mathrm{N}, 126^{\circ} 37^{\prime} \mathrm{E}^{1}$ & 74 & 27 & 101 \\
\hline & Forest & Sun Island & $45^{\circ} 48^{\prime} \mathrm{N}, 126^{\circ} 36^{\prime} \mathrm{E}$ & 15 & 78 & 93 \\
\hline \multirow{2}{*}{ Changchun } & City & Chongqing Road & $43^{\circ} 53^{\prime} \mathrm{N}, 125^{\circ} 20^{\prime} \mathrm{E}$ & 17 & 9 & 26 \\
\hline & Forest & Jingyue Pool & $43^{\circ} 48^{\prime} \mathrm{N}, 125^{\circ} 27^{\prime} \mathrm{E}$ & 32 & 20 & 52 \\
\hline \multirow{2}{*}{ Shenyang } & City & Shengyang Middle Street & $41^{\circ} 48^{\prime} \mathrm{N}, 123^{\circ} 27^{\prime} \mathrm{E}$ & 48 & 12 & 60 \\
\hline & Forest & Shenyang Expo Garden & $41^{\circ} 52^{\prime} \mathrm{N}, 123^{\circ} 39^{\prime} \mathrm{E}$ & 11 & 5 & 16 \\
\hline \multirow{2}{*}{ Beijing } & City & Tiananmen Square & $39^{\circ} 55^{\prime} \mathrm{N}, 116^{\circ} 24^{\prime} \mathrm{E}$ & 323 & 178 & 501 \\
\hline & Forest & Beijing Olympic Park & $39^{\circ} 60^{\prime} \mathrm{N}, 116^{\circ} 24^{\prime} \mathrm{E}$ & 63 & 28 & 91 \\
\hline \multirow{2}{*}{ Tianjin } & City & Binjiang Road & $39^{\circ} 08^{\prime} \mathrm{N}, 117^{\circ} 12^{\prime} \mathrm{E}$ & 179 & 52 & 231 \\
\hline & Forest & Tanggu Forest Park & $39^{\circ} 05^{\prime} \mathrm{N}, 117^{\circ} 41^{\prime} \mathrm{E}$ & 8 & 6 & 14 \\
\hline \multirow{2}{*}{ Taiyuan } & City & Wuyi Square & $38^{\circ} 52^{\prime} \mathrm{N}, 112^{\circ} 34^{\prime} \mathrm{E}$ & 10 & 3 & 13 \\
\hline & Forest & Yingze Park & $37^{\circ} 51^{\prime} \mathrm{N}, 112^{\circ} 34^{\prime} \mathrm{E}$ & 13 & 3 & 16 \\
\hline \multirow{2}{*}{ Jinan } & City & Quancheng Park & $36^{\circ} 40^{\prime} \mathrm{N}, 117^{\circ} 01^{\prime} \mathrm{E}$ & 114 & 27 & 141 \\
\hline & Forest & Jinan Forest Park & $36^{\circ} 40^{\prime} \mathrm{N}, 116^{\circ} 57^{\prime} \mathrm{E}$ & 11 & 1 & 12 \\
\hline \multirow{2}{*}{ Nanjing } & City & Nanjing Confucius Temple & $32^{\circ} 01^{\prime} \mathrm{N}, 118^{\circ} 47^{\prime} \mathrm{E}$ & 148 & 51 & 199 \\
\hline & Forest & Laoshan National Forest Park & $32^{\circ} 04^{\prime} \mathrm{N}, 118^{\circ} 34^{\prime} \mathrm{E}$ & 7 & 10 & 17 \\
\hline \multirow{2}{*}{ Hefei } & City & Municipal Government Park & $31^{\circ} 52^{\prime} \mathrm{N}, 117^{\circ} 17^{\prime} \mathrm{E}$ & 29 & 3 & 32 \\
\hline & Forest & Dashushan Forest Park & $31^{\circ} 50^{\prime} \mathrm{N}, 117^{\circ} 10^{\prime} \mathrm{E}$ & 29 & 10 & 39 \\
\hline \multirow{2}{*}{ Shanghai } & City & The Bund of Shanghai & $31^{\circ} 14^{\prime} \mathrm{N}, 121^{\circ} 29^{\prime} \mathrm{E}$ & 199 & 81 & 280 \\
\hline & Forest & Gongqing Forest Park & $31^{\circ} 19^{\prime} \mathrm{N}, 121^{\circ} 33^{\prime} \mathrm{E}$ & 69 & 20 & 89 \\
\hline \multirow{2}{*}{ Hangzhou } & City & Hangzhou Yan'an Road & $30^{\circ} 15^{\prime} \mathrm{N}, 120^{\circ} 10^{\prime} \mathrm{E}$ & 141 & 15 & 156 \\
\hline & Forest & Hangzhou West Lake & $30^{\circ} 15^{\prime} \mathrm{N}, 120^{\circ} 09^{\prime} \mathrm{E}$ & 274 & 98 & 372 \\
\hline \multirow{3}{*}{ Guangzhou } & City & Shangxiajiu Pedestrian Street & $23^{\circ} 07^{\prime} \mathrm{N}, 113^{\circ} 15^{\prime} \mathrm{E}$ & 84 & 25 & 109 \\
\hline & Forest & Huolushan Forest Park & $23^{\circ} 11^{\prime} \mathrm{N}, 113^{\circ} 24^{\prime} \mathrm{E}$ & 107 & 57 & 164 \\
\hline & & & Total & 2005 & 819 & 2824 \\
\hline
\end{tabular}

Note: ${ }^{1}$ Coordinates stand for locations of the central part of each place.

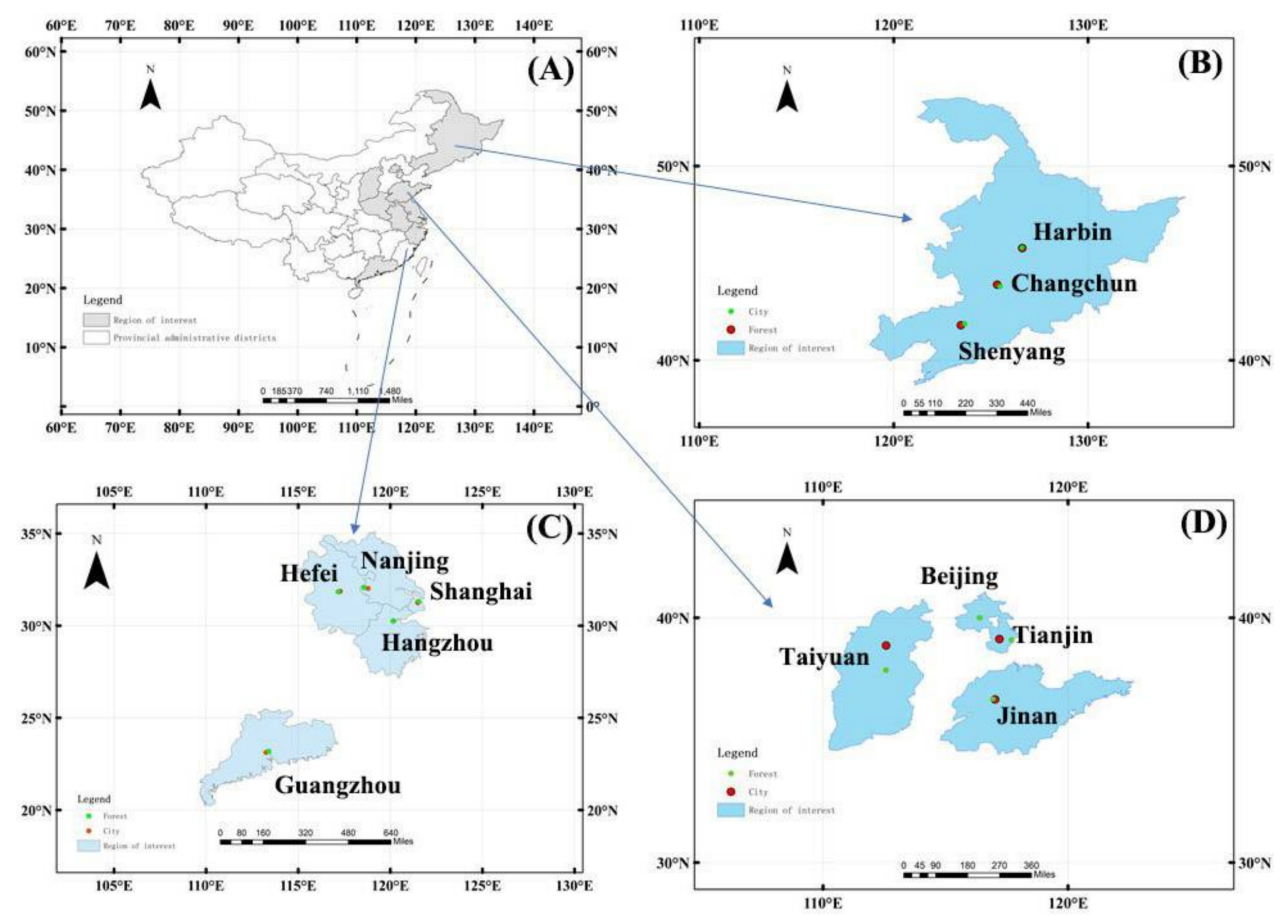

Figure 1. Distributions of study areas (A) in northeast (B), southern (C), and central (D) China. Forest locations are labelled by green dots and city locations by red dots. 


\subsection{Photo Treatment and Analysis}

Collected photos were screened for their availability for further analysis. Photos could be documented for further analysis only when facial organs (eyes, eyebrows, nose, mouth, and ears) were clear without over-decoration or shielding. Photos with multiple people were cropped into smaller-sizes with only one individual per photo. Processed photos were further rotated so that the nose was perpendicular to the horizontal frame of the photo. All photos were marked with the date taken. This procedure will be useful to match facial data with meteorological records. Afterwards, photos were evaluated for the gender and age of subjects. Treated photos were analyzed with FireFACE ${ }^{\mathrm{TM}}$ software V1.0 (Zhilunpudao Agricultural Science \& Technique Inc., Changchun, China) for happy and sad expressional scores. Photos were imported to the software panel where results on happy and sad scores were given after clicking the "analyze" button. Emotions of a random face can contain happy, sad, and neutral emotions and the software also gave scores of neutral expressions (e.g., Figure S1). FireFACE V1.0 software will give scores of the three types of facial expressions in percent, and the sum of frequencies of three expressions is 100\%. We did not include the neutral scores because they were irrelevant to this study. Examples of typical happy and sad expressions that were analyzed and rated by the FireFACE software can be found in the Supplemental Figure. The software was trained by 30,000 photos in advance to obtain the optimum matching rate. More details about the software can be found in Wei et al. [31]. Details of the panel operation can be found in Wei et al. [30]. Validation was not necessary for happy and sad expressions because they are the two basic expressions that obtained highest matching accuracies among all types of expressions $[29,39]$.

\subsection{Statistical Analysis}

The positive response index (PRI) was used in this study to evaluate net positive emotional responses. According to previous studies [30,31], the PRI was calculated as the happy score minus the sad score. This variable was used as an available tool to reveal net emotions on the faces of forest experiencers [28-30]. Either positive or negative values can be obtained for PRI results.

Factors of different cities $(n=12)$ and places (forest vs. urban) were considered as two sources of variance to test whether the response of facial expressions in different places varied with the change of cities. The evaluated gender (female vs. male) and age (toddler, youth, middle, and senior) of visitors were also considered as factors that can impact facial expression scores. The range of ages for toddlers, youths, middle-aged people, and senior citizens were visually evaluated by mechanicians according to their experience within ranges of $0-5,15-25,30-60$, and over 60 years old, respectively [29]. The four factors were tested as fixed effects in the analysis of variance (ANOVA) on the expression scores. When data did not follow normal distribution, expression scores were ranked in ANOVA to transform them such that they were distribution-free [40]. However, when means were calculated, the data were transformed back [41]. When a significant effect was indicated, means were compared with Duncan test at the 0.05 significance level to cope with the uneven numbers of replicates among groups of data. Stepwise regression was used to assess the effects of environmental factors and topographic gradients (independent variables) on happy and sad scores and PRI (dependent variables). Multiple regression was also used to evaluate the co-driving forces of the environmental factors on facial expressions. Statistics and fit-plots were finished using SAS software (SAS Institute, Cary, NC, USA) with detailed programs given by previous studies [42-44]. Bar charts were made using SigmaPlot v.14.0 software (Systat Software, Inc., San Jose, CA, USA) [45].

\section{Results}

\subsection{Happy Score}

City, place, gender, and age did not have any interactive effects on happy scores (Table 2). Instead, each of them had a single effect as the main factor. Among cities, 
happy scores were higher in Hefei than most of other cities, but the difference between Changchun and Guangzhou were not statistically different (Figure 2A). Variation in place had a significant effect on happy scores, which were higher for people in forest settings than in urban settings (Figure 2B). Gender difference was significant. Females showed higher happy scores than males (Figure 2C). Age had a significant effect. Happy scores had a generally negative relationship with age (Figure 2D). In addition, senior citizens showed lower happy scores than toddlers and youths.

Table 2. Analysis of variance (ANOVA) of effects from different cities (City), places in cities (Place), gender of visitors (Gender), age of visitors (Age), and their interactions on happy and sad expression scores (rank-transformed) on faces of visitors in urban promenades vs. forests during the National Day of China in 2018.

\begin{tabular}{|c|c|c|c|c|c|c|c|}
\hline \multirow{2}{*}{ Source } & \multirow{2}{*}{$D F^{1}$} & \multicolumn{2}{|c|}{ Happy } & \multicolumn{2}{|c|}{ Sad } & \multicolumn{2}{|c|}{ PRI $^{2}$} \\
\hline & & F Value & $p$ Value & $F$ Value & $p$ Value & $F$ Value & $p$ Value \\
\hline Model & 128 & $3.66^{3}$ & $<0.0001$ & 2.98 & $<0.0001$ & 3.65 & $<0.0001$ \\
\hline Error & 2695 & - & - & - & - & - & - \\
\hline City & 11 & $2.47^{3}$ & 0.0045 & 3.36 & 0.0001 & 3.58 & $<0.0001$ \\
\hline Place & 1 & 33.43 & $<0.0001$ & 36.76 & $<0.0001$ & 40.44 & $<0.0001$ \\
\hline Gender & 1 & 267.65 & $<0.0001$ & 71.22 & $<0.0001$ & 189.45 & $<0.0001$ \\
\hline Age & 3 & 9.57 & $<0.0001$ & 30.83 & $<0.0001$ & 26.04 & $<0.0001$ \\
\hline City $\times$ Place & 11 & 1.61 & 0.0889 & 1.89 & 0.0358 & 1.96 & 0.0286 \\
\hline City $\times$ Gender & 11 & 0.56 & 0.862 & 0.49 & 0.9116 & 0.32 & 0.9821 \\
\hline City $\times$ Age & 25 & 1.18 & 0.2446 & 1.34 & 0.1233 & 1.11 & 0.3158 \\
\hline Place $\times$ Gender & 1 & 0.38 & 0.5392 & 0.02 & 0.8843 & 0.06 & 0.8039 \\
\hline Place $\times$ Age & 2 & 2.61 & 0.0734 & 3.66 & 0.0258 & 0.0258 & 0.0091 \\
\hline Gender $\times$ Age & 2 & 0.34 & 0.714 & 1.5 & 0.2238 & 0.69 & 0.5013 \\
\hline City $\times$ Place $\times$ Gender & 11 & 0.63 & 0.8086 & 0.93 & 0.508 & 0.77 & 0.6714 \\
\hline City $\times$ Place $\times$ Age & 16 & 1.05 & 0.4012 & 0.82 & 0.6614 & 0.73 & 0.7649 \\
\hline Place $\times$ Gender $\times$ Age & 2 & 0.82 & 0.4416 & 1.93 & 0.1448 & 1.59 & 0.205 \\
\hline City $\times$ Place $\times$ Gender $\times$ Age & 31 & 0.87 & 0.6676 & 1.47 & 0.1066 & 1.06 & 0.3735 \\
\hline
\end{tabular}

Note: ${ }^{1} D F$, degree of freedom; ${ }^{2}$ PRI, positive response index; ${ }^{3}$ values in bold font indicate significant effect from ANOVA.

\subsection{Sad Score}

The difference in sad scores between cities was significant (Table 2). People in Beijing, Nanjing, and Tianjin showed the highest level of sad scores, which were evaluated as $23.19 \pm 15.99 \%$ (percent mean \pm standard deviation, the same below), $22.50 \pm 14.53 \%$, and $22.00 \pm 13.30 \%$, respectively. Urban and forest settings showed contrasting effects on sad scores, which was higher for people in promenades $(21.73 \pm 3.72 \%)$ than in forests $(15.35 \pm 6.63 \%)$ by $41.63 \%$. Gender also had a significant effect on sad scores. Males had higher sad scores $(24.58 \pm 24.39 \%)$ than females $(17.74 \pm 12.46 \%)$ by $39.18 \%$. Sad scores showed an increasing trend along the age gradient. Sad scores for toddlers $(13.51 \pm 18.06 \%)$ and youth $(16.43 \pm 10.34 \%)$ were lower than those in senior citizens $(37.24 \pm 29.43 \%)$. Sad scores for middle-aged people $(26.73 \pm 17.44 \%)$ were not statistically different from those of other age groups.

City and place had an interactive effect on sad scores (Table 2). We did not find a significant difference in sad scores between visitors in urban and forest places in the same city. Statistics revealed that sad scores in the forests of Hefei were lower than that in the promenades of Beijing and Nanjing (Figure 3A). The sad score in Hefei forests was also lower than that in Shenyang forests.

Place and age also had an interactive effect on sad scores. Toddlers in forests showed lower sad scores than toddlers in urban settings and middle-aged visitors and senior citizens in urban settings (Figure 3B). In contrast to happy scores, male visitors showed higher sad scores than females (Figure 3C). 

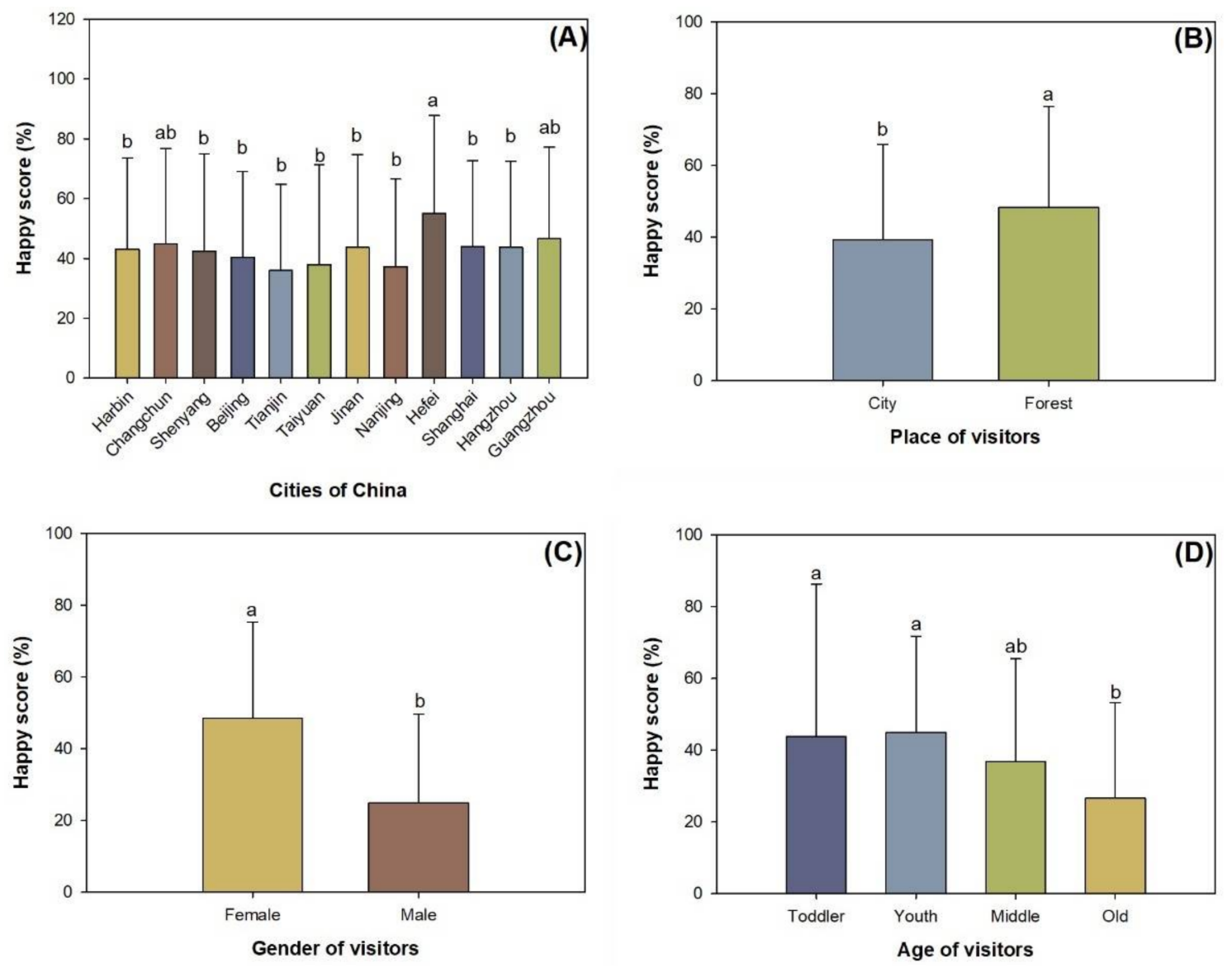

Figure 2. Happy scores on visitor faces in 12 cities (A) between city vs. forest places (B) with varied genders (C) and ages (D) during the National Day of China in 2018. Error bars stand for standard errors that started from the columns (means) and do not show the lower extremity. Different letters of a and b indicate significant differences of ranked scores according to a Duncan test at the 0.05 level.

\subsection{Positive Response Index}

City, place, gender, and age had a single effect as the main factor on PRI (Table 2). The positive response index was higher in Hefei $(43.35 \pm 11.94 \%)$ than in most of the other cities except for Guangzhou (31.69 $\pm 14.80 \%)$. Compared to people in urban settings, those in forest settings had an $88.28 \%$ greater PRI $(17.50 \pm 17.04 \%$ and $32.94 \pm 13.99 \%$, respectively). Females had higher PRI ( $30.87 \pm 16.21 \%)$ compared to males $(0.27 \pm 1.93 \%)$. With the increase of age, PRI generally showed a decreasing trend. Toddlers and youth had a higher PRI ( $30.27 \pm 17.63 \%$ and $28.46 \pm 13.96 \%$, respectively) than senior citizens $(-10.68$ $\pm 17.69 \%$ ), while the PRI for middle-aged visitors $(10.13 \pm 10.50 \%)$ was not statistically different from those of other age groups.

City and place also had an interactive effect on PRI (Figure 4A). There was no difference in PRI between visitors in urban and forest settings in the same city. Visitors in forest settings in Shenyang showed a lower PRI than those in forests at Beijing, Hefei, and Guangzhou. Age and gender also had an interactive effect on PRI (Table 2). Senior citizens in urban settings had a lower PRI than toddlers in forests (Figure 4B). Females had a higher PRI than males (Figure 4C).

\subsection{Regression Analysis}

Minimum daily temperature was the only environmental factor that imposed a positive driving force for happy scores (Table 3). Latitude had contrasting effects on sad scores and PRI. When latitude increased, sad scores declined, but PRI tended to increase. 
As shown in Figure 5A, as minimum temperature increased, ranked happy scores increased with the lowest $95 \%$ confidence limits in the range of approximately $12-13{ }^{\circ} \mathrm{C}$. Similarly, as latitude increased, ranked sad scores increased, as did the lowest $95 \%$ confidence limits in the range of $31-32^{\circ}$ (Figure 5B). According to the city list in Table 1, the latitudes of Nanjing, Hefei, and Shanghai fell in this range, which had relatively lower errors in the increase of sad scores compared to other cities. Additionally, these three cities also had the lowest $95 \%$ confidence limits for decreasing PRI relative to the increase of latitude (Figure 5C).
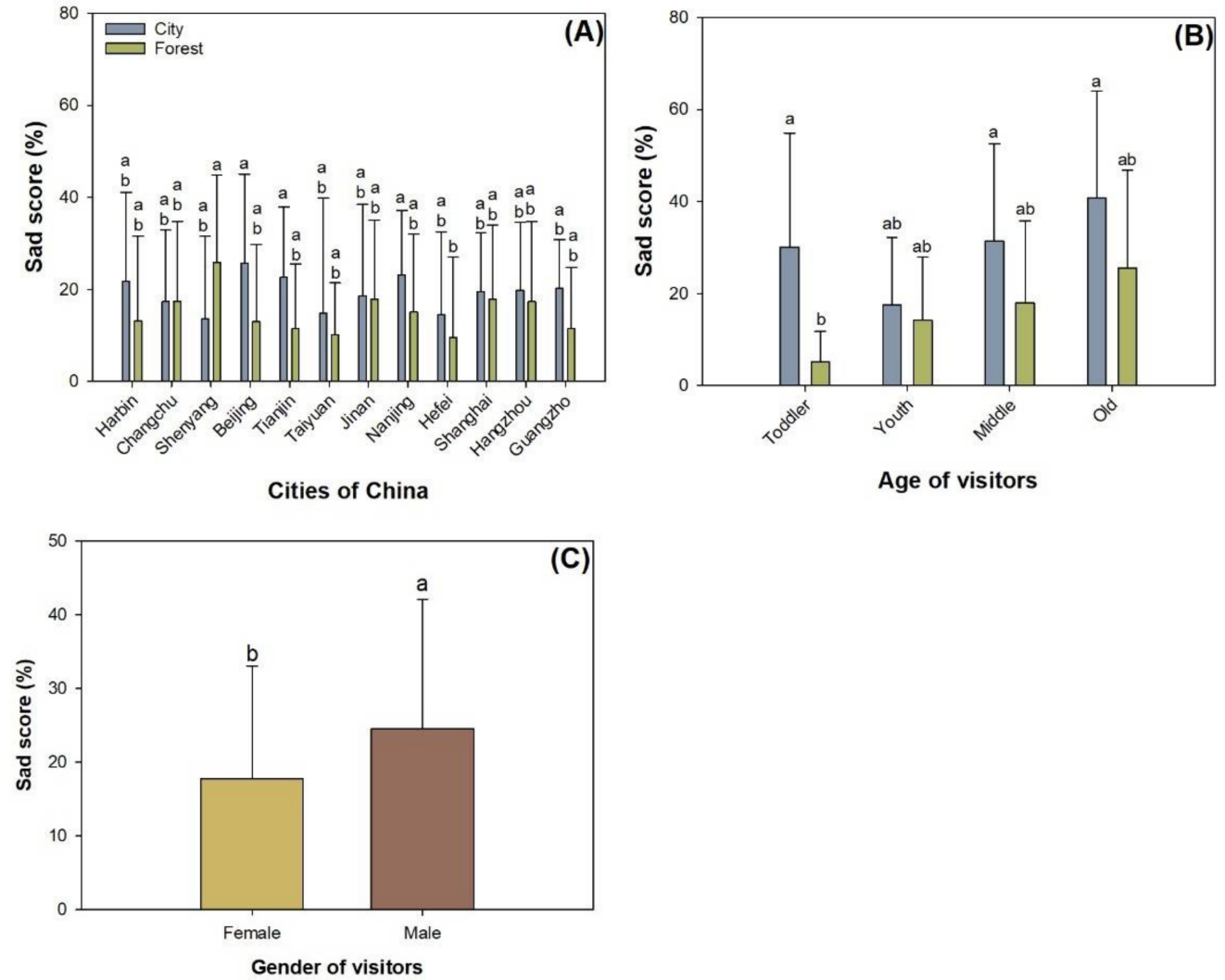

Figure 3. Sad scores on faces of visitors in city promenades vs. urban forests in 12 cities (A) with varied ages and genders at different places $(\mathbf{B})$ and contrasting genders $(\mathbf{C})$ during the National Day of China in 2018. Error bars stand for standard errors that started from the columns (means) and did not show lower extremity. Different letters of $a$ and $b$ indicate significant differences of ranked scores according to a Duncan test at the 0.05 level.

Table 3. Stepwise regression of daily maximum and minimum levels of temperature and relative humidity and latitude and longitude degrees to happy and sad expression scores (rank-transformed) on faces of visitors in urban promenades vs. forests during the National Day of China in 2018.

\begin{tabular}{ccccccc}
\hline \multirow{2}{*}{ Parameter } & Coefficient & $\begin{array}{c}\text { Parameter } \\
\text { Estimate }\end{array}$ & $\boldsymbol{S E}^{\mathbf{1}}$ & Model $\boldsymbol{R}^{\mathbf{2}}$ & $\boldsymbol{F}$ value & $\boldsymbol{P r}>\boldsymbol{F}$ \\
\hline \multirow{2}{*}{ Happy } & Intercept & 1310.84 & 47.08 & - & 775.05 & $<0.0001$ \\
& MinT $^{2}$ & 7.45 & 3.26 & 0.0018 & 5.21 & 0.0225 \\
\hline \multirow{2}{*}{ Sad } & Intercept & 1141.74 & 89.35 & - & 163.30 & $<0.0001$ \\
& Latitude & 7.83 & 2.54 & 0.0033 & 9.46 & 0.0021 \\
\hline \multirow{2}{*}{ PRI $^{3}$} & Intercept & 1685.24 & 89.35 & - & 355.78 & $<0.0001$ \\
& Latitude & -7.88 & 2.54 & 0.0034 & 9.60 & 0.0020 \\
\hline
\end{tabular}

Note: ${ }^{1}$ SE, standard error; ${ }^{2}$ MinT, Minimum daily temperature; ${ }^{3}$ PRI, positive response index. 


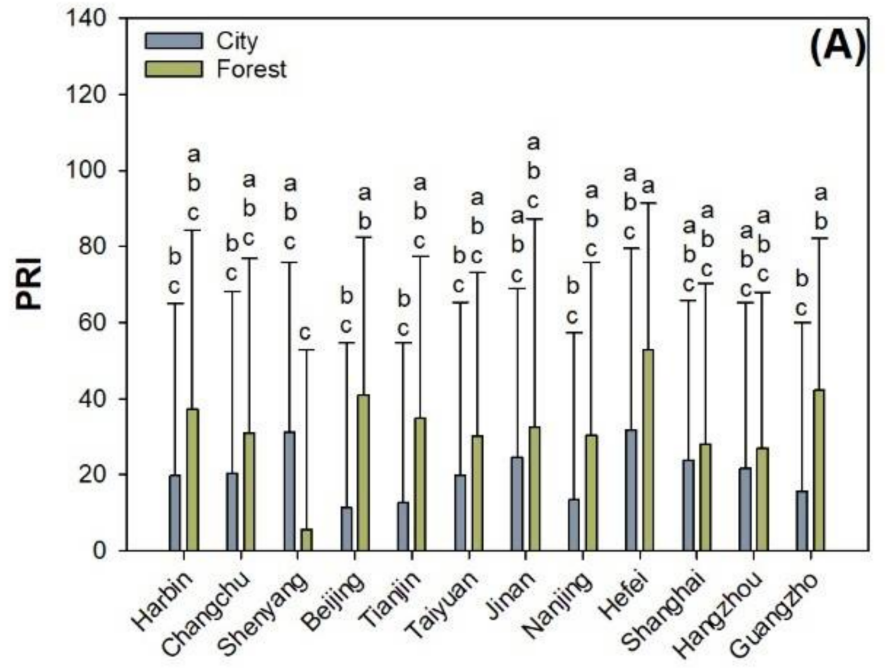

Cities of China

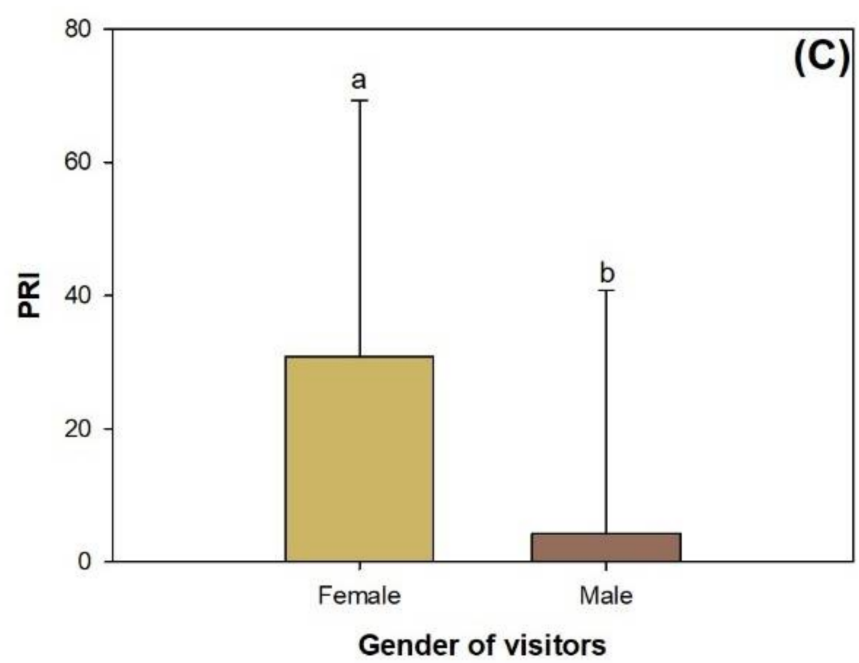

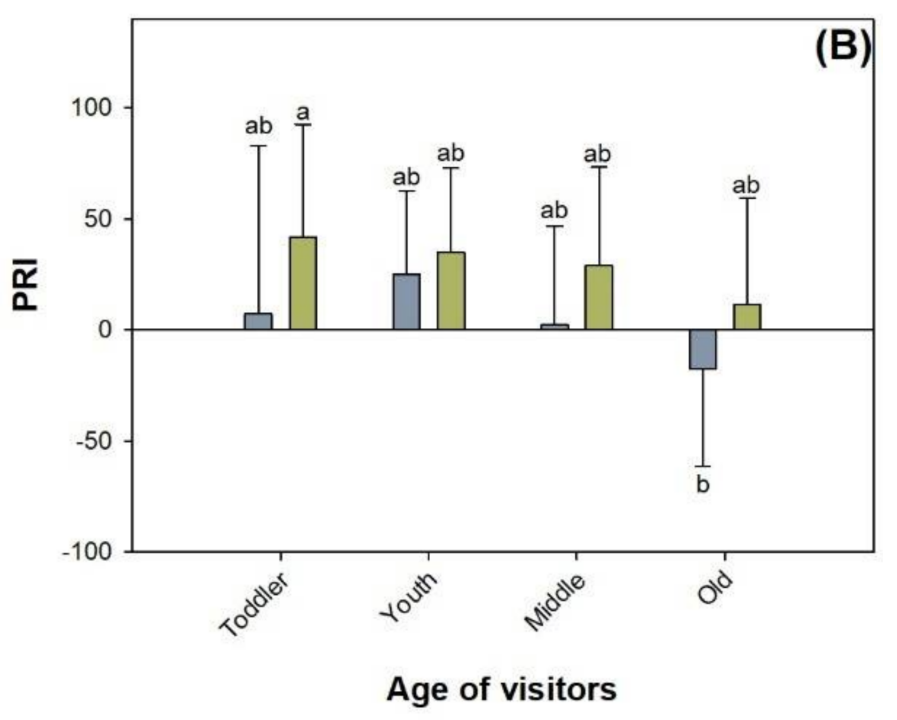

Figure 4. Positive response index (PRI) on faces of visitors in city promenades vs. urban forests in 12 cities (A) with varied ages and genders at different places (B) or contrasting genders (C) during the National Day of China in 2018. Error bars stand for standard errors that started from the columns (means) and did not show lower extremity. Different letters of a and $\mathrm{b}$ indicate significant differences of ranked scores according to the Duncan test at the 0.05 level. 

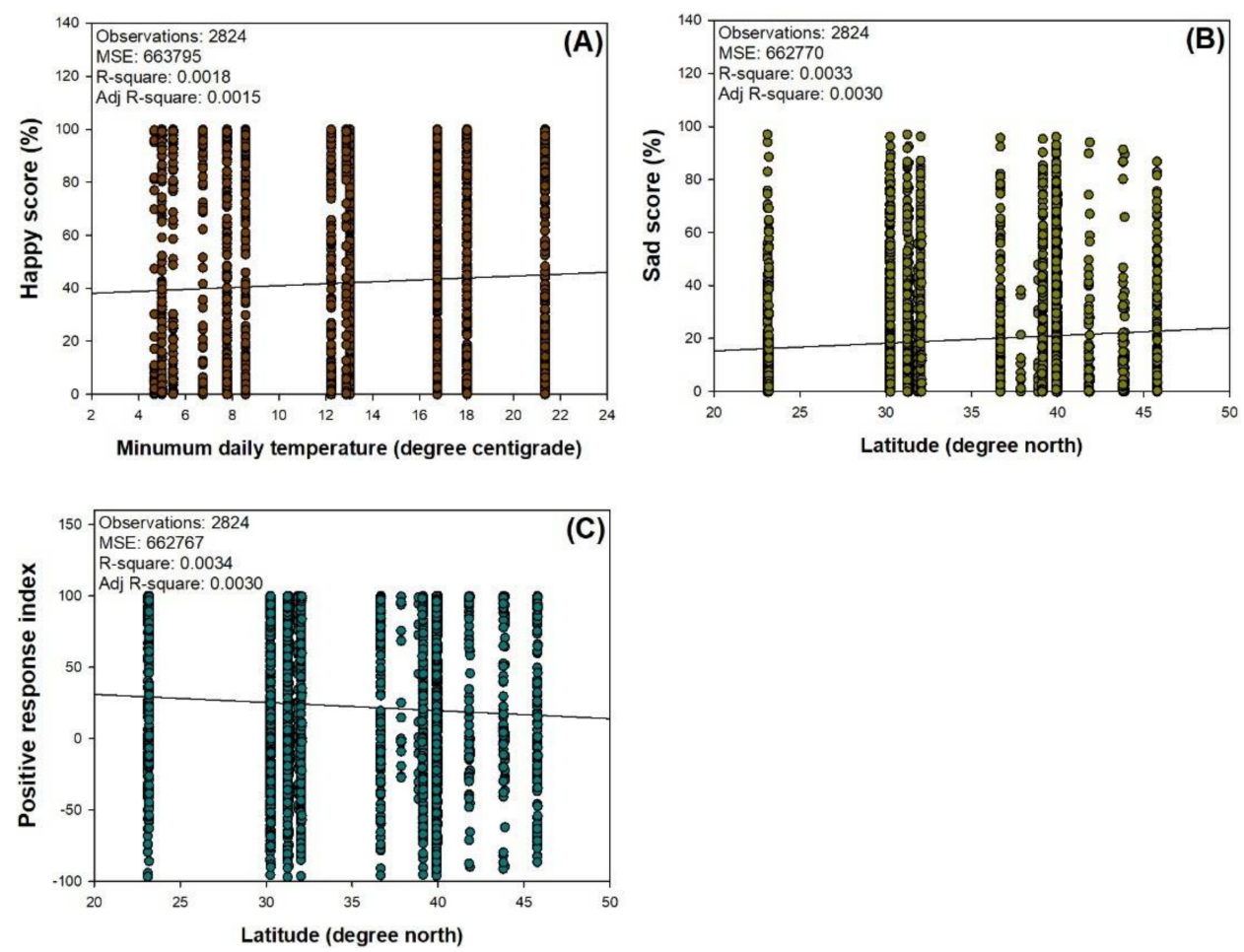

Figure 5. Fit plots of linear regression of minimum temperature to happy scores (A), latitude to sad scores (B), and PRI (C). Lines are the fit curse in a linear correlation model. Regression coefficients are calculated using ranked data. Regression parameters are adapted from the stepwise regression models in Table 3. Abbreviations as follows: MSE, mean standard error; R-square, squared regression coefficient of determination; adj R-square: adjusted squared regression coefficient of determination.

\section{Discussion}

\subsection{More Positive Emotion in Forests Than in Cities}

According to our findings, we can only partly accept our first hypothesis. Happiness was the only variable that was significantly different between forest and urban settings. These results concur with those found in a local-scale study on facial expressions of visitors in a forest park and a street in the same city [30]. In our study, people in forests had higher happy scores of approximately $50 \%$ compared to people in promenades with happy scores of about $40 \%$. This difference resulted in a $23 \%$ gross increase in happy score, which is nearly the same as a $27 \%$ increase in the local study [30]. These results suggest that our results for the happy scores were reliable, and similar to smaller-scale studies. However, there were no differences in happy scores for people who did not actively experience the forest and urban settings [29]. Two explanations can account for this difference. First, happy scores found by Wei et al. [29] were collected neither by a crossover design nor by a change of places. People were photographed at a fixed place (forest park entrance/exit) and the variance in forest vs urban places originated by distinguishing walking orientations. Perhaps the positive emotion perceived by people is only distinct in forests located at different places. Secondly, people may feel and show more happy emotions before and during holidays than when not celebrating holidays [46]. This may at least partly promote the level of happy emotions in forests. However, we compared the facial expressions of people at different places in the same period; hence the variation between holidays and ordinary days had no effect on our results. Our hypotheses need more work to certify or supplement with more detailed evidence.

In our study, PRI is a different variable from the happy score, as the former reflects the net positive emotions on a face and the latter reflects the absolute extent of happy emotion. Expressions on our faces hint at multiple emotions as a complex rather than any single emotion [47]. The use of PRI can eliminate any negative emotions that can be 
aroused with even strong stimuli [48]. The difference between forest and urban settings at different places did not evoke significant responses in sad scores and PRI. Our sad scores fell in the $10-40 \%$ range, and the PRI fell in the $-10-50 \%$ range. These ranges were much narrower than those found in a local forest park [29] or in regional forests in northeast China [28] (both within 0-100\%). Therefore, our study lowered the possible frequency of errors because of the larger amount of data availability. Although city and place had an interactive effect on sad scores and PRI, no significant differences of these two variables were found in any single city. The difference in sad scores between forest and urban settings were from visitors in two different cities. This did not support the idea that forest settings can evoke positive emotions compared to urban settings in the same city, as was indicated in studies using questionnaires [13,49]. The difference in PRI was only found in forests from different cities. This suggests that different locations in a wide geographical range can have greater effects on visitors' emotions than contrasting environments in the same city. Our results on PRI differed from those of the local-scale studies where forest experiencers showed higher PRI than urban experiencers [31]. However, the variation of cities was also found to be the main explanation for the variance of the negative emotion scores for northeast cities [28].

\subsection{Gender Effect on Facial Expressions}

Our results on three variables (city variation, gender, and age) showed a strong trend that females showed more positive and less negative emotional expressions than males. Females were also reported to show more happy faces than males in a regional investigation on cities in Northeast China [28]. In a pilot study with crossover questionnaires, females were also found to obtain more emotional well-being from a forest experience in winter through alleviation of stress and improvement of mood states [24,50]. A meta-analysis across studies on psychological differences between sexes supported our finding that females appeared to more naturally show positive emotional behaviors. It was suggested that, in biological and socialization theories, males were more apt to hide their emotional expressions and show calm faces, but females were socialized to express more positive emotions [51]. In contrast, gender did not affect visitors in forest and urban settings [29]. Because we did not find any interactive effects between gender and place, we surmise that positive expression by females in forests may be inherent to socialized behavior rather than a response to a forest experience. More studies are needed at a similar or larger geographical scale to determine the objectivity of our surmise.

\subsection{Age Effect on Facial Expressions}

It was interesting to find that age appeared to have a negative impact on positive expressions. Toddlers showed more happy expressions than senior citizens, although the effect on PRI came from an interaction with place. Our results greatly differed from those in the pilot study, where age had no effect on happy scores and senior citizens showed more positive expressions than younger ones when combined with place and time [29]. To our knowledge, it is difficult to find references or explanations that account for our findings regarding the effect of age on happy scores. In contrast, toddlers in forest settings showed the lowest level of sad emotions, compared to youth, middle-aged people, and seniors in urban settings. Toddlers were also found to report more positive emotions when close to nature in comparison to an experience in the museum [52]. Children with improved mood expressed eagerness to get close to nature and a strong will to protect nature. Although some toddlers also reported extremely negative emotions, their response was caused by disappointment in being separated from nature. Therefore, we consider that a forest experience would mentally benefit toddlers more than adult urban experiencers. We determined the age of photographed subjects by visual assessment. This approach was also used to determine age in studies on urban forest experiencers [29,39]. Manual assessment of age was also used in a study on public sentimental response during the pandemic with large-scale big data [53]. Although artificial intelligence instruments can be 
used to recognize the age of people in photos [54], their ability is trained by a dataset that was classified by people [31]. Because of the unevenness among studies and insufficient evidence for an explanation, we suggest more studies to replicate our findings.

\subsection{Driving Forces from Environmental Factors}

Only the minimum temperature contributed to happy scores. The improvement of psychological state was also reported by studies using questionnaires [32]. Although other physiological factors such as relative humidity and wind velocity may have had a close relationship with the change in temperature, their contributions to sad expression scores were covered by the gradient of latitude. Latitude gradients may generate an integrated impact on sad scores with a combination of several environmental factors $[37,38]$. Environmental factors had no contributions to the sad expression scores in our study, which concurs with earlier findings from a pilot investigation [29]. In contrast, a longterm investigation found that weather conditions such as precipitation, temperature, and humidity were all associated with worsened expressions [55]. To our knowledge, we cannot give a certified explanation for the null response of sad expression scores to climatic conditions. As our results about sad expression scores were generally the opposite of those on happy expression scores, we surmise that a forest experience directly affects the positive emotions of people while sad emotions are directly and negatively linked to happy sentiments, but not directly impacted by climate. More work is needed to certify this surmise and determine more confirmative explanations.

Humidity was found to have a significant impact on mood state in local-scale studies [30,32], but in our study, that was not the case. People may be sensitive to regional relative humidity because their feelings are transitory and responsive. As a short-term driver, humidity is easily perceived by people as a facial expressional response. However, humidity may lose its influence on emotional perception in large scale studies because the range of variance is too big to generate strong, within-group errors.

Temperature in urban forests can evoke positive emotions for visitors [32], but not for forests in the spring season of temperate cities [30]. In contrast, cooling can bring psychological well-being in the forests of Shanghai during early summertime [56]. The range of comfortable temperatures in urban forests exist between $12.1^{\circ} \mathrm{C}$ to $21.6^{\circ} \mathrm{C}$ [57]. A range matched our predicted values along the fit curve with the lowest errors. Studies at a local scale tended to report emotional responses to temperature as a casual case with low chances to be replicated in another place or at a different time of the year. Investigation at a large geographical range covers a large group of people in different places at different times. Their common responses showed a general trend of positive emotion with increases of temperature. New investigations are needed to verify our findings on the positive emotional responses to increases in temperature. Maybe more cities, or cities in a special climatic region, can be included in future studies.

Along the latitude gradient, people in northern areas had more negative expressions, and in contrast, less positive emotions, than those in southern areas. This agrees with our findings on happy expressions because northern cities are generally colder than southern cities during most of the year. These results concur with findings in a previous study, where the facial expressions of people in three cities in Northeast China were compared [28]. Cities in the suggested geographic range with predicted negative emotions at a high confidence were located around the Yangtze River delta, which is one of the most-developed regions in China. As this region is located in the subtropical climatic zone, annual temperature is warmer than in northern cities. However, scholars have suggested that, due to the high speed of economic and urbanization developments, people in cities of this region have suffered extreme temperature events for at least 30 years [58-60]. We believe extreme temperature events drove the high prediction confidence of negative emotion expressions on the faces of people in the Yangtze River delta. More confirmative results need future work to verify. 


\subsection{Limits of the Study}

Although we aimed to compare settings of forest parks and adjacent promenades and squares in the same city, the choice of urban settings can be more specific to eliminate possible impacts from inner-group difference. For example, both Tiananmen Square and the Bund of Shanghai were taken as references of squares in Beijing and Shanghai, respectively. They had contrasting architecture styles and people can rarely have same emotional perceptions to these two places. Secondly, although we used data from 12 random cities in eastern regions of China, our data may have suffered strong variation due to the differences of the dimensions in our cities. As an alternative strategy to cope with this issue, future work is suggested to test the facial expressions of urban forest visitors in cities that were classified into different types to determine specific responses to each type of city. Thirdly, our age range may have suffered from a great deal of uncertainty because we divided ages according to what people looked like. Our young and middle-aged people may fall in the different age ranges than they would have in Wei et al. [29]. Different ages had an available meaning to make population distinctions between different types of people, but comparison across studies on ages of people is meaningless unless a powerful standard is published to categorize people's age according to their photos. Finally, we only made simple comparisons of emotional expressions between urban and forest settings across different cities. The application of our results was limited to evidence-based design and urban planning because a 'healing garden' needs a design with much more complicated landscape architecture practices to offer certain kinds of interaction between construction and nature $[61,62]$. For example, an alternating change of colors using deciduous trees in forest landscapes can evoke a more active effect on patients suffering from psychotic disorders [62]. Future studies focusing on landscape design are suggested to solve the issue of the specific responses of facial expressions to complicated relationships between architecture and nature.

\section{Conclusions}

Our study on 12 cities and 2824 photos of happy and sad expressions revealed that experiences in forest settings can elicit a higher frequency of happy faces than those in urban environment. A forest experience alone does not counter negative emotional expressions. Instead, the age of people also needs to be considered. Gender had a strong effect on emotional expressions, and females showed more positive emotional expressions than males, but it was unlikely to be the result of a forest experience alone. The frequency of happy faces increased with increases in minimum temperature, and sad faces appeared more frequently in northern cities. Overall, forest setting experiences can evoke positive emotions, which is likely due to comfortable feelings in warm temperatures.

Supplementary Materials: The following are available online at www.mdpi.com/article/10.3390/ su13168687/s1, Figure S1: The panel of FireFACE software V1.0 to recognize photos with typically happy, sad, and neutral facial expressions. The model is the Japanese entertainer Ryoko Hirosue. This figure has also been used as an example in a published study of Wei et al. [31].

Author Contributions: Conceptualization, P.L. and H.W.; methodology, Y.W. and H.W.; software, P.L. and M.L.; validation, M.L., T.X. and Y.W.; formal analysis, T.X. and Y.W.; investigation, M.L. and T.X.; resources, P.L.; data curation, M.L. and H.W.; writing-original draft preparation, P.L., M.L. and T.X.; writing-review and editing, Y.W. and H.W.; visualization, T.X.; supervision, P.L.; project administration, P.L.; funding acquisition, P.L. All authors have read and agreed to the published version of the manuscript.

Funding: This research was funded by the Liaoning Key R\&D Program (grant number: 2020JH2/ 10200033), the Central Financial Forestry Science and Technology Promotion Demonstration Fund Project (grant number: Grant No.Liao[2017]TG10), and the National Natural Science Foundation of China (grant numbers: 42001117, 41971122, and 41861017).

Institutional Review Board Statement: The study was conducted according to the guidelines of the Declaration of Helsinki, and approved by the Ethics Committee of Research Group of Urban Forests 
and Wetlands, Northeast Institute of Geography and Agroecology, Chinese Academy of Sciences (protocol code UFW-EC-2018-001; 5 June 2018).

Informed Consent Statement: Informed consent was given by the open-access policy of the platform where all subjects were involved in the study.

Data Availability Statement: Not applicable.

Acknowledgments: Dan Wang, Xin Chen, and Lingquan Meng are acknowledged for their great contributions as mechanicians to collect data about facial expression scores and regional climate factors.

Conflicts of Interest: The authors declare no conflict of interest.

\section{References}

1. Pykett, J.; Osborne, T.; Resch, B. From Urban Stress to Neurourbanism: How Should We Research City Well-Being? Ann. Am. Assoc. Geogr. 2020, 110, 1936-1951. [CrossRef]

2. Nieuwenhuijsen, M.J.; Khreis, H. Car free Cities: Pathway to healthy urban living. Environ. Int. 2016, 94, 251-262. [CrossRef] [PubMed]

3. European Environment Agency. Urban Adaptation to Climate Change in Europe 2016-Transforming Cities in a Changing Climate; Publications Office of the European Union: Luxembourg, 2016.

4. Zhou, C.W.; Yan, L.B.; Yu, L.F.; Wei, H.X.; Guan, H.M.; Shang, C.F.; Chen, F.Y.; Bao, J.Z. Effect of Short-term Forest Bathing in Urban Parks on Perceived Anxiety of Young-Adults: A Pilot Study in Guiyang, Southwest China. Chin. Geogr. Sci. 2019, 29, 139-150. [CrossRef]

5. Guan, H.; Wei, H.; He, X.; Ren, Z.; An, B. The tree-species-specific effect of forest bathing on perceived anxiety alleviation of young-adults in urban forests. Ann. For. Res. 2017, 60, 327-341. [CrossRef]

6. Ulrich, R.S.; Simons, R.F.; Losito, B.D.; Fiorito, E.; Miles, M.A.; Zelson, M. Stress recovery during exposure to natural and urban environments. J. Environ. Psychol. 1991, 11, 201-230. [CrossRef]

7. Baum, A.; Fleming, R.; Singer, J.E. Understanding environmental stress: Strategies for conceptual and methodlogical integration. In Advances in Environmental Psychology; Baum, A., Singer, J.E., Eds.; Lawrence Erlbaum Associates: Hillsdale, NJ, USA, 1985; Volume 5, pp. 185-205.

8. $\quad$ Diener, E.; Suh, E.M.; Lucas, R.E.; Smith, H.L. Subjective well-being: Three decades of progress. Psychol. Bull. 1999, 125, $276-302$. [CrossRef]

9. Grossman, P.; Niemann, L.; Schmidt, S.; Walach, H. Mindfulness-based stress reduction and health benefits-A meta-analysis. J. Psychosom. Res. 2004, 57, 35-43. [CrossRef]

10. Coldwell, D.F.; Evans, K.L. Visits to urban green-space and the countryside associate with different components of mental well-being and are better predictors than perceived or actual local urbanisation intensity. Landsc. Urban Plan. 2018, 175, 114-122. [CrossRef]

11. Nitoslawski, S.A.; Galle, N.J.; Van den Bosch, C.K.; Steenberg, J.W.N. Smarter ecosystems for smarter cities? A review of trends, technologies, and turning points for smart urban forestry. Sust. Cities Soc. 2019, 51, 101770. [CrossRef]

12. Kabisch, N.; Puffel, C.; Masztalerz, O.; Hemmerling, J.; Kraemer, R. Physiological and psychological effects of visits to different urban green and street environments in older people: A field experiment in a dense inner-city area. Landsc. Urban Plan. 2021, 207, 103998. [CrossRef]

13. Kobayashi, H.; Ikei, H.; Song, C.; Kagawa, T.; Miyazaki, Y. Comparing the impact of forest walking and forest viewing on psychological states. Urban For. Urban Green. 2021, 57, 126920. [CrossRef]

14. Stigsdotter, U.K.; Corazon, S.S.; Sidenius, U.; Kristiansen, J.; Grahn, P. It is not all bad for the grey city-A crossover study on physiological and psychological restoration in a forest and an urban environment. Health Place 2017, 46, 145-154. [CrossRef] [PubMed]

15. Vert, C.; Gascon, M.; Ranzani, O.; Marquez, S.; Triguero-Mas, M.; Carrasco-Turigas, G.; Arjona, L.; Koch, S.; Llopis, M.; DonaireGonzalez, D.; et al. Physical and mental health effects of repeated short walks in a blue space environment: A randomised crossover study. Environ. Res. 2020, 188, 109812. [CrossRef] [PubMed]

16. Triguero-Mas, M.; Gidlow, C.J.; Martínez, D.; de Bont, J.; Carrasco-Turigas, G.; Martínez-Íñiguez, T.; Hurst, G.; Masterson, D.; Donaire-Gonzalez, D.; Seto, E.; et al. The effect of randomised exposure to different types of natural outdoor environments compared to exposure to an urban environment on people with indications of psychological distress in Catalonia. PLoS ONE 2017, 12, e0172200. [CrossRef]

17. Kotera, Y.; Richardson, M.; Sheffield, D. Effects of Shinrin-Yoku (Forest Bathing) and Nature Therapy on Mental Health: A Systematic Review and Meta-analysis. Int. J. Ment. Health Addict. 2020, 2020, 1-25. [CrossRef]

18. Kaplan, R.; Kaplan, S. The Experience of Nature: A Psychological Perspective; Cambridge University Press: New York, NY, USA, 1989.

19. Pihel, J.; Ode Sang, Å.; Hagerhall, C.; Nyström, M. Expert and novice group differences in eye movements when assessing biodiversity of harvested forests. For. Policy Econ. 2015, 56, 20-26. [CrossRef]

20. Aerts, R.; Honnay, O.; Van Nieuwenhuyse, A. Biodiversity and human health: Mechanisms and evidence of the positive health effects of diversity in nature and green spaces. Br. Med. Bull. 2018, 127, 5-22. [CrossRef] 
21. Ekman, P.; Davidson, J.R. The Nature of Emotion: Fundamental Questions; Oxford University Press: New York, NY, USA, 1994.

22. Wikipedia Contributors. Emotion. Available online: https: / / en.wikipedia.org $/ \mathrm{w} /$ index.php?title=Emotion\&oldid=1018211762 (accessed on 18 April 2021).

23. Bielinis, E.; Janeczko, E.; Takayama, N.; Zawadzka, A.; Slupska, A.; Pietka, S.; Lipponen, M.; Bielinis, L. The effects of viewing a winter forest landscape with the ground and trees covered in snow on the psychological relaxation of young Finnish adults: A pilot study. PLoS ONE 2021, 16, e0244799. [CrossRef]

24. Bielinis, E.; Lukowski, A.; Omelan, A.; Boiko, S.; Takayama, N.; Grebner, D.L. The Effect of Recreation in a Snow-Covered Forest Environment on the Psychological Wellbeing of Young Adults: Randomized Controlled Study. Forests 2019, 10, 827. [CrossRef]

25. Takayama, N.; Korpela, K.; Lee, J.; Morikawa, T.; Tsunetsugu, Y.; Park, B.J.; Li, Q.; Tyrvainen, L.; Miyazaki, Y.; Kagawa, T. Emotional, Restorative and Vitalizing Effects of Forest and Urban Environments at Four Sites in Japan. Int. J. Environ. Res. Public Health 2014, 11, 7207-7230. [CrossRef]

26. McEwan, K.; Giles, D.; Clarke, F.J.; Kotera, Y.; Evans, G.; Terebenina, O.; Minou, L.; Teeling, C.; Basran, J.; Wood, W.; et al. A Pragmatic Controlled Trial of Forest Bathing Compared with Compassionate Mind Training in the UK: Impacts on Self-Reported Wellbeing and Heart Rate Variability. Sustainability 2021, 13, 1380. [CrossRef]

27. Wikipedia Contributors. Facial Expression. Available online: https://en.wikipedia.org/w/index.php?title=Facial_expression\& oldid=1011786479 (accessed on 25 April 2021).

28. Wei, H.; Hauer, R.J.; Chen, X.; He, X. Facial expressions of visitors in forests along the urbanization gradient: What can we learn from selfies on social networking services? Forests 2019, 10, 1049. [CrossRef]

29. Wei, H.; Hauer, R.J.; He, X. A forest experience does not always evoke positive emotion: A pilot study on unconscious facial expressions using the face reading technology. For. Policy Econ. 2021, 123, 102365. [CrossRef]

30. Wei, H.; Ma, B.; Hauer, R.J.; Liu, C.; Chen, X.; He, X. Relationship between environmental factors and facial expressions of visitors during the urban forest experience. Urban For. Urban Green. 2020, 53, 126699. [CrossRef]

31. Wei, H.; Hauer, R.J.; Zhai, X. The relationship between the facial expression of people in university campus and host-city variables. Appl. Sci. 2020, 10, 1474. [CrossRef]

32. Park, B.J.; Furuya, K.; Kasetani, T.; Takayama, N.; Kagawa, T.; Miyazaki, Y. Relationship between psychological responses and physical environments in forest settings. Landsc. Urban Plan. 2011, 102, 24-32. [CrossRef]

33. Kim, S.S.; Song, K.S.; Go, J.H. A Study of design with spatial rule-based engine using geospatial big-data. In Proceedings of the 2018 International Conference on Information and Communication Technology Convergence, Jeju, Korea, 17-19 October 2018; pp. 1273-1275.

34. Wikipedia Contributors. National Day of the People's Republic of China. Available online: https:/ / en.wikipedia.org/w/index. php?title=National_Day_of_the_People\%27s_Republic_of_China\&oldid=1023749763 (accessed on 18 May 2021).

35. Dai, L.; Xue, T.; Wu, B.; Rong, X.; Xu, B. Spatiotemporal Structure Features of Network Check-in Activities of Urban Residents and Their Impacting Factors: A Case Study in Six Urban Districts of Beijing. J. Asian Archit. Build. Eng. 2017, 16, 131-138. [CrossRef]

36. Climatic Data Centre. Meteorological Data Centre of China Meteorological Administration. Available online: http://data.cma.cn/ (accessed on 18 April 2021).

37. Guo, S.L.; Wei, H.X.; Li, J.P.; Fan, R.F.; Xu, M.Y.; Chen, X.; Wang, Z.Y. Geographical Distribution and Environmental Correlates of Eleutherosides and Isofraxidin in Eleutherococcus senticosus from Natural Populations in Forests at Northeast China. Forests 2019, 10, 872. [CrossRef]

38. Guo, S.L.; Zhang, D.H.; Wei, H.Y.; Zhao, Y.N.; Cao, Y.B.; Yu, T.; Wang, Y.; Yan, X.F. Climatic Factors Shape the Spatial Distribution of Concentrations of Triterpenoids in Barks of White Birch (Betula Platyphylla Suk.) Trees in Northeast China. Forests 2017, 8, 334. [CrossRef]

39. Wei, H.X.; Liu, P. The accuracy validation of FireFACE software in analyzing facial expressions of urban forest visitors. Preprints 2020, 265. [CrossRef]

40. Conover, W.J.; Iman, R.L. Rank Transformations as a Bridge between Parametric and Nonparametric Statistics. Am. Stat. 1981, 35, 124-129.

41. Sloan, J.L.; Burney, O.T.; Pinto, J.R. Drought-Conditioning of Quaking Aspen (Populus tremuloides Michx.) Seedlings during Nursery Production Modifies Seedling Anatomy and Physiology. Front. Plant Sci. 2020, 11, 11. [CrossRef]

42. Baiyi, A.N.; Hongxu, W.E.I.; Linlin, L.I.; Peng, G.U.O. Nutrient Uptake and Utilization and Antioxidants of Fruits in Red Raspberry (Rubus idaeus L.) Cultivar 'Autumn Bliss' in response to Fertilization under Extended Photoperiod. Not. Bot. Horti Agrobot. 2018, 46, 440-448.

43. Hongxu, W.E.I.; Hengtian, Z.; Xin, C. Foliar N:P Stoichiometry in Aralia elata Distributed on Different Slope Degrees. Not. Bot. Horti Agrobot. 2019, 47, 887-895.

44. Li, X.; Xia, H.; Wang, J.; Chen, Q. Nutrient uptake and assimilation in fragrant rosewood (Dalbergia odorifera T.C. Chen) seedlings in growing media with un-composted spent mushroom residue. PLOS ONE 2021, 16, e0249534.

45. Liu, P.; Cao, B.; Wang, Y.; Wei, Z.; Ye, J.; Wei, H. Spectral effect of streetlamps on urban trees: A simulated study on tissue water, nitrogen, and carbohydrate contents in maple and oak. PLOS ONE 2021, 16, e0248463.

46. Nawijn, J.; Marchand, M.A.; Veenhoven, R.; Vingerhoets, A.J. Vacationers Happier, but Most not Happier After a Holiday. Appl. Res. Qual. Life 2010, 5, 35-47. [CrossRef] 
47. Du, S.; Tao, Y.; Martinez, A.M. Compound facial expressions of emotion. Proc. Natl. Acad. Sci. USA 2014, 111, E1454-E1462. [CrossRef] [PubMed]

48. Kerrihard, A.L.; Khair, M.B.; Blumberg, R.; Feldman, C.H.; Wunderlich, S.M. The effects of acclimation to the United States and other demographic factors on responses to salt levels in foods: An examination utilizing face reader technology. Appetite 2017, 116, 315-322. [CrossRef] [PubMed]

49. Yu, C.P.; Lin, C.M.; Tsai, M.J.; Tsai, Y.C.; Chen, C.Y. Effects of Short Forest Bathing Program on Autonomic Nervous System Activity and Mood States in Middle-Aged and Elderly Individuals. Int. J. Environ. Res. Public Health 2017, 14, 897. [CrossRef] [PubMed]

50. Bielinis, E.; Takayama, N.; Boiko, S.; Omelan, A.; Bielinis, L. The effect of winter forest bathing on psychological relaxation of young Polish adults. Urban For. Urban Green. 2018, 29, 276-283. [CrossRef]

51. Chaplin, T.M. Gender and Emotion Expression: A Developmental Contextual Perspective. Emot. Rev. 2014, 7, 14-21. [CrossRef] [PubMed]

52. Dopko, R.L.; Capaldi, C.A.; Zelenski, J.M. The psychological and social benefits of a nature experience for children: A preliminary investigation. J. Environ. Psychol. 2019, 63, 134-138. [CrossRef]

53. Zhu, J.; Xu, C. Sina microblog sentiment in Beijing city parks as measure of demand for urban green space during the COVID-19. Urban For. Urban Green. 2021, 58, 126913. [CrossRef]

54. Zhu, X.; Gao, M.; Zhang, R.; Zhang, B. Quantifying emotional differences in urban green spaces extracted from photos on social networking sites: A study of 34 parks in three cities in northern China. Urban For. Urban Green. 2021, 62, 127133. [CrossRef]

55. Baylis, P.; Obradovich, N.; Kryvasheyeu, Y.; Chen, H.; Coviello, L.; Moro, E.; Cebrian, M.; Fowler, J.H. Weather impacts expressed sentiment. PLoS ONE 2018, 13, e0195750. [CrossRef] [PubMed]

56. Elsadek, M.; Liu, B.Y.; Lian, Z.F.; Xie, J.F. The influence of urban roadside trees and their physical environment on stress relief measures: A field experiment in Shanghai. Urban For. Urban Green. 2019, 42, 51-60. [CrossRef]

57. Jeong, M.A.; Park, S.; Song, G.S. Comparison of human thermal responses between the urban forest area and the central building district in Seoul, Korea. Urban For. Urban Green. 2016, 15, 133-148. [CrossRef]

58. Kong, Q.Q.; Ge, Q.S.; Xi, J.C.; Zheng, J.Y. Human-biometeorological assessment of increasing summertime extreme heat events in Shanghai, China during 1973-2015. Theor. Appl. Climatol. 2017, 130, 1055-1064. [CrossRef]

59. Qian, Z.H.; Cao, C.H.; Feng, G.L. Spatial distribution characteristics of nearly extremely anomalous temperature events in summer and winter in China. Acta Phys. Sin. 2017, 66, 049201.

60. Gao, J.J.; Yu, F.; Xu, Z.H.; Duan, J.; Cheng, Q.; Bai, L.J.; Zhang, Y.W.; Wei, Q.N.; Yi, W.Z.; Pan, R.B.; et al. The association between cold spells and admissions of ischemic stroke in Hefei, China: Modified by gender and age. Sci. Total Environ. 2019, 669, 140-147. [CrossRef] [PubMed]

61. Paraskevopoulou, A.T.; Kamperi, E. Design of hospital healing gardens linked to pre-or post-occupancy research findings. Front. Archit. Res. 2018, 7, 395-414. [CrossRef]

62. Paraskevopoulou, A.T.; Kamperi, E.; Demiris, N.; Economou, M.; Theleritis, C.; Kitsonas, M.; Papageorgiou, C. The impact of seasonal colour change in planting on patients with psychotic disorders using biosensors. Urban For. Urban Green. 2018, 36, 50-56. [CrossRef] 